\title{
SOBRE LA ABDUCCIÓN
}

\begin{abstract}
«Quien se guiase por la lógica podría inferir de una gota de agua la posibilidad de la existencia de un Océano Atlántico o de un Niágara sin necesidad de haberlos visto u oído hablar de ellos».
\end{abstract}

HOLMES, Sh., «El libro de la vida»

\section{INTRODUCCIÓN}

o descubrí que usted había venido del Afganistán. Por la fuerza de
un largo hábito, el curso de mis pensamientos es tan rígido en mi
cerebro, que llegué esa conclusión sin tener siquiera conciencia de
las etapas intermedias. Sin embargo, pasé por esas etapas. El curso
de mi razonamiento fue el siguiente: «He aquí a un caballero que responde al tipo del hombre de Medicina, pero que tiene un aire marcial. Es, por consiguiente, un médico militar con toda evidencia. Acaba de llegar de países tropicales, porque su cara es de un fuerte color oscuro, color que no es natural de su cutis, porque sus muñecas son blancas. Ha pasado por sufrimientos y enfermedad, como lo pregona su cara macilenta. Ha sufrido una herida en el brazo izquierdo. Lo mantiene rígido y de una manera forzada... ¿En qué país tropical ha podido un médico del Ejército inglés pasar por duros sufrimientos y resultar herido en un brazo? Evidentemente, en el Afganistán». Toda esa trabazón de pensamientos no me llevó un segundo. Y entonces hice la observación de que usted había venido del Afganistán, lo cual lo dejó asombrado».

De esta manera describe Sherlock Holmes, en la primer novela que protagoniza ${ }^{1}$, el procedimiento por el cual llega a conocer que Watson había estado en Afganistán. Holmes sostiene que su método debe «tanto a la observación como a la deducción», y de hecho el capítulo del cual se extrajeron tanto estos ejemplos como la frase que abre el trabajo se denomina: «La ciencia de la deducción». Sin embargo, pareciera que en este tipo de procedimientos la deducción

${ }^{1}$ Conan Doyle, 1887: 27-28. 
y la observación solas no bastan, se intuye la presencia de otros elementos relevantes para explicar el proceso que lleva a la solución de un problema como el presentado.

Así lo entienden la mayoría de los autores que tratan el tema, el que por otra parte ha llamado la atención desde distintas áreas ${ }^{2}$ y al que se ha intentado explicar diversas maneras.

Lo que motiva estos trabajos es la creencia de que elucidando el procedimiento utilizado paradigmáticamente en las novelas policiales podría lograrse un aporte importante a la metodología de la investigación científica. Dicho procedimiento parece ser el mismo que se emplea en cualquier investigación tendente a resolver un problema. El aspecto más relevante consiste en que con el mismo se puede abarcar la actividad generadora de nuevos conocimientos, comúnmente ubicada en el denominado «contexto de descubrimiento». $\mathrm{Si}$ se logra dar cuenta de estos procedimientos entonces también podría hablarse de «métodos de descubrimiento», los que si bien distarían de ser de aplicación mecánica, permitirín ampliar el marco de racionalidad, acotado generalmente al «contexto de justificación» y restringido al uso de la lógica deductiva.

Comencé a interesarme en la cuestión, pues entreví la posibilidad de utilizarla con provecho en el estudio de ciertos aspectos del fenómeno jurídico. Principalmente la imaginé como la herramienta teórica capaz de dar cuenta de una de las tareas más importantes que se llevan a cabo en un proceso judicial: la prueba de los hechos.

Como señala el profesor Atienza, «la mayor parte de los problemas sobre los que tienen que conocer y decidir tanto los tribunales como los órganos no jurisdiccionales de la Administración son más bien problemas concernientes a los hechos, de manera que los argumentos que tienen lugar con ocasión de los mismos caen fuera del campo de estudio de las teorías usuales de la argumentación jurídica» (1991:20). Esta situación justificaba el tratamiento exploratorio de la cuestión, como punto de partida de un trabajo más amplio que puede ser de gran utilidad tanto para el jurista teórico como para el práctico.

Una de las reconstrucciones más comunes del trabajo del detective parte de la obra de Charles Sanders Peirce, y cree reconocer en el

${ }^{2}$ Desde la semiótica (Eco: 1983), hasta la lógica (Hintikka: 1982), pasando por la historia (Ginzburg: 1979), se ha considerado importante analizar esta cuestión. Atienza (1991: 37) también se ocupa de la misma, mencionando las posibilidades de utilización en el campo jurídico. 
procedimiento detectivesco el tipo de argumento al que Peirce denominó «abducción». De hecho, el filósofo ejemplifica en una de sus obras dicha inferencia con un caso similar al presentado al comienzo del trabajo (1892a: 271-272).

Uno de los epistemólogos contemporáneos que más ha defendido la abducción (a la que denomina retroducción) como método de descubrimiento fue Norwood Russell Hanson. Sostiene que los enfoques hipotético-deductivistas no pueden dar cuenta de ciertos procedimientos que los científicos utilizan racionalmente cuando intentan explicar fenómenos problemáticos. Dado que históricamente puedenencontrarse documentados estos procesos (Galileo, Kepler) los mismos no pueden ser ignorados por la epistemología. La explicación de estos procesos de descubrimiento por ende es la tarea que cumple la abducción.

Este trabajo persigue los siguientes objetivos: i) analizar los trabajos de Peirce y Hanson a los efectos de lograr una reconstrucción de la abducción/retroducción que aclare el alcance con que se utiliza la expresión en dichos autores; ii) indagar la viabilidad de la abducción como método de descubrimiento, señalando los problemas que se deben resolver antes de su aceptación; iii) mostrar que a pesar de que el planteo hipotético-deductivo de Popper puede dar cuenta de muchos de los aspectos que Hanson le atribuye en exclusividad a la abducción, el mismo Popper parece abrir la posibilidad de un desarrollo complementario de su propia concepción del descubrimiento científico. De sus propios escritos surge el espacio metodológico para una operación que, llámese o no abducción, tiende a hacer difusos los límites entre contexto de descubrimiento y contexto de justificación.

\section{LA ABDUCCIÓN COMO MÉTODO DE DESCUBRIMIENTO}

\section{Introducción: el planteo de Schuster}

El profesor Félix Schuster en su exposición en el «Primer Coloquio Bariloche de Filosofía» realizado en 1992 (luego recogida en un artículo publicado en 1993), sostuvo que la construcción de un modelo racional de ciencia no debía estar rígidamente ligado al ámbito de la justificación, sino que existía la posibilidad de ampliarlo al campo del descubrimiento o la producción de conocimiento. La estrategia que exploró Schuster para conseguir este objetivo es la de discutir la posibilidad de una lógica del descubrimiento.

Reconoce que para poder discutir esta posibilidad previamente se deben superar ciertas cuestiones definicionales, como: i) evitar la 
posición que sostiene que donde aparece la lógica ya se está en el contexto de justificación; ii) extender el concepto de lógica al de metodología; iii) reconocer la relevancia de los métodos en este intento de ampliar el ámbito de la racionalidad sin identificar método con racionalidad, pues esta última noción debe incorporar necesariamente la consideración de otros factores.

Partiendo de su tesis del pluralismo metodológico en las ciencias sociales [desarrollado con amplitud en Schuster (1992)], sostiene que son varios los métodos posibles para el descubrimiento. Analiza como ejemplos el método empleado por Marx en «El Capital», el método progresivo-regresivo planteado por Lefevre y recogido por Sartre y la abducción-retroducción a partir de los trabajos de Peirce y Hanson.

En relación a la abducción-retroducción afirma:

«(...) También la abducción (Peirce) ha sido reivindicada como posible método de descubrimiento, con una estructura que puede formularse así: 'Un (sorprendente) fenómeno F aparece. La hipótesis H permite explicar adecuada y corrientemente a F. Por consiguiente, hay buenas razones para suponer que la hipótesis $\mathrm{H}$ es verdadera'. Hanson menciona este procedimiento bajo el nombre de retroducción. Un inconveniente de la abducción, en tanto método para descubrir hipótesis, es que la hipótesis ya aparece en las premisas». (Schuster, 1992: 17).

«La inducción puede constituir un método descubrimiento, o también la abducción-retroducción (vía Peirce-Hanson): Un sorprendente fenómeno F emerge, aparece. La hipótesis $\mathrm{H}$ permite explicar adecuada y corrientemente a F. Por tanto, hay buenas razones para suponer que la hipótesis $\mathrm{H}$ es verdadera».

«Peirce consideraba que la abducción tenía una forma lógica definida, que él representaba así:

El sorprendente hecho $\mathrm{C}$ es observado. Pero si A fuera verdadera, C sería corriente. De aquí resulta que hay razones para suponer que A es verdadera».

«Como el mismo Peirce observó, la hipótesis A ya está contenida en las premisas, por lo que esta manera de argumentar no puede representar, literalmente, la secuencia de pasos que conducen a la hipótesis». (Schuster, 1993: 208).

Es cierto lo que sostiene el profesor Schuster al valorar la abducción, pues si se reconoce como reconstrucción de la misma los 
esquemas presentados anteriormente, es evidente que dado que la hipótesis ya está contenida en las premisas es difícil poder considerarla como un posible «método de descubrimiento», pues nada parece sugerir sobre el origen de la misma.

Pero lo evidente que resultan estas razones es lo que nos obliga a dudar de las mismas. Existe una incompatibilidad entre las expresiones de Peirce de estar ante el único procedimiento capaz de generar nuevo conocimiento o de Hanson de haber hallado el enfoque que supere las limitaciones de las posturas hipotético-deductivas y la reconstrucción que se toma como base para criticar sus posiciones.

Creemos que tanto Peirce como Hanson tienen que haber justificado mejor sus asertos, por lo que indagaremos en sus obras a los efectos de buscar una reconstrucción de la abducción/retroducción más defendible que la utilizada por Schuster, desde la que realizar un análisis crítico cuyos resultados no puedan ser cuestionados por partir de una versión debilitada de la propuesta de dichos autores. Al mismo tiempo permitirá señalar aquellos aspectos de la abducción que deben mejorarse antes de intentar obtener algún provecho de su utilización. También reconstruiremos la versión popperiana del descubrimiento científico a los efectos de dejar en claro las relaciones que guardan ambas propuestas.

\section{La abducción en la obra de Charles S. Peirce ${ }^{3}$}

Peirce utiliza la expresión «abducción» («hipótesis», «razonamiento hipotético»o «retroducción») $)^{4}$ en contextos diferentes y con alcances distintos en cada caso: Filosofía de la mente, Lógica, Semiótica, Metodología.

\footnotetext{
${ }^{3}$ La obra del filósofo norteamericano Charles S. Peirce (1839-1914) se halla dispersa en diferentes artículos y textos particulares. No publicó en vida ningún libro, y la obra de referencia más conocida es una selección y reagrupación de los mismos denominada Collected Papers (1931-1958), que consta de ocho volúmenes.

Las traducciones castellanas del mismo son a su vez parciales, es decir selecciones de esa selección. Esto constituye un problema al momento de reconstruir los aspectos de su pensamiento que nos interesan, dado que no se tiene la seguridad de haber podido relevar todos los textos que tratan la cuestión.

No obstante, a partir de las compilaciones que se señalan en la bibliografía y de las obras que analizan el tema de la abducción es posible intentar dicha reconstrucción tomando los recaudos del caso.

${ }^{4}$ Todas estas expresiones serán utilizadas con el mismo sentido. Algunos autores piensan que Peirce distingue entre abducción e hipótesis, según el procedimiento culmine con la fijación de una ley general o en la explicación de un hecho particular (Eco; 1983b: 273-4). Esta interpretación no parece ajustarse al tratamiento que Peirce hace de la cuestión. Las siguientes citas muestran cómo utiliza las diferentes
} 
Dado que el interés inicial de Peirce es ampliar la lista de categorías kantianas en la construcción de la estructura que crea las posibilidades de todo conocimiento ${ }^{5}$, y dado que en Kant la lógica ocupa un lugar importantísimo en dicha tarea, su primera mención se produce en dicho terreno. Para Kant el tipo de inferencia deductiva irreductible era Barbara, Peirce por su parte ampliará esta lista agregando la inducción y la abducción a partir de combinaciones en los enunciados que componen la estructura silogística mencionada, a los que denomina «regla», «caso» y «resultado» según su ubicación en dicho esquema.

La caracterización como argumento válido ${ }^{6}$, común en todos los trabajos que intentan explicar las ideas de Peirce, parte de lo que éste denomina «silogismos explicativos» de cada inferencia, los que se pueden graficar de la siguiente manera:

\begin{tabular}{lll} 
Deducción & Inducción & Abducción \\
\hline Regla & Caso & Regla \\
Caso & Resultado & Resultado \\
Resultado & Regla & Caso \\
Rnteo lógico de Peirce expuesto anteriormente se basa principalmente
\end{tabular}

expresiones indistintamente en contextos similares: [1] «Hay tres tipos de razonamiento: deducción, inducción y abducción (...)» (1903b: 130); [2] «Las tres clases principales de inferencia lógica son: deducción, inducción e hipótesis(...)» (1892a: 270); [3] Asimismo, en una nota de la compilación de José Vericat (1988: 400, nota 5) se cita el siguiente fragmento de los Collected Papers que avalan nuestra interpretación: «En ciencia, hay tres modos de razonar fundamentalmente diferentes: deducción (...), inducción (...) y retroducción (...)».

${ }^{5}$ Pilar Castillo Criado en la introducción a Peirce, 1968, pág. 14. La importancia que el autor da a Kant puede apreciarse claramente en (Peirce, 1865).

${ }^{6}$ La lógica para Peirce puede entenderse en un sentido amplio como semiótica general (1903a: 169) y en un sentido estricto como lógica crítica, encargada de la clasificación de los argumentos (1901a). A su vez puede encuadrársela en el conjunto de las ciencias normativas como dependiente de la Ética y de la Estética (1903/1906). No detallaremos el por qué de estas distinciones ni la justificación de las relaciones que establece entre las disciplinas, pues excedería el marco de este trabajo. Sin embargo, vale su mención para mostrar que no estamos ante un filósofo convencional, y al mismo tiempo apoyar la decisión tomada en el sentido de evitar asumir su trama teórica global sin discusión para trabajar con la abducción.

En un artículo publicado en 1867 y denominado «Sobre la clasificación natural de los argumentos» (1867a), Peirce justifica la existencia de tres razonamientos irreductibles: deducción, inducción e hipótesis. Dicha justificación se lleva a cabo en términos exclusivamente lógicos, pero tomando como única referencia la silogística de tradición aristotélica. 
en los siguientes presupuestos: i) toma como teoría lógica básica la silogística de tradición aristotélica, asumiendo que la tarea de la lógica es clasificar los argumentos dentro de ese marco teórico; ii) se maneja con un concepto particular de validez que permite considerar válidos esquemas inferenciales susceptibles de permitir el paso de premisas verdaderas a conclusiones falsas.

Ninguno de estos supuestos puede ser aceptado a la luz de la lógica tal como se la concibe comúnmente hoy en día ${ }^{7}$, por lo que debemos tratar de caracterizar la abducción en base a textos en los que Peirce utilice otros medios para dar cuenta de ella.

Esto obliga a deslizar el terreno de caracterización de la abducción del plano lógico al plano metodológico, a los efectos de determinar si la misma puede ser reconstruida con provecho con independencia de los aspectos erróneos con la que se la intentó justificar. De lo contrario, habría que concluir que la imposibilidad de fundarla lógicamente nos obliga a eliminarla del discurso epistemológico. Esto no se condice con la actualidad del debate en torno a la abducción ni con el rol que Peirce le asigna en muchos de sus escritos, por lo que consideramos que antes de tomar una decisión tan drástica es menester agotar todas las perspectivas desde las que dicha operación pueda cumplir alguna función relevante desde el punto de vista epistemológico.

\subsection{La abducción en el con texto metodológico}

La metodología que utilizamos para construir este aparatado fue la siguiente: partimos de una serie de textos de Peirce que caracterizan a la abducción, tratamos de analizarlos en detalle (muchos parecían contradecirse entre sí) a los efectos de intentar una reconstrucción de la abducción como método que conjugue todos los elementos compatibles que habíamos identificado.

Recurrimos a algunas citas indirecta de Peirce con el objeto de morigerar el efecto que sobre nuestras conclusiones podría tener la

${ }^{7}$ La silogística de tradición aristotélica que toma como base es un sistema defectuoso y superado. pues por una parte no puede dar cuenta de muchos razonamientos válidos muy comunes, y por otra lleva a considerar como correctos esquemas inferenciales cuyas premisas no garantizan por sí solas la verdad de la conclusión. Cfr. Quine (1944: 86 y ss.) y (1950: 124 y ss.). Al mismo tiempo la utilización de un concepto de validez tan amplio que le permite fundar la validez lógica de la inducción no sería aceptado en la actualidad ni aun por aquellos autores propensos a sostener posturas flexibles al respecto. Cfr. Haack (1978: 34). 
circunstancia desafortunada de no haber podido relevar todos los textos de Peirce de interés para la cuestión.

En los escritos publicados en los últimos años del siglo pasado, Peirce caracterizaba la abducción de una manera muy similar a la inducción, lo que podía llevar a considerar a la abducción como una especie particular de inducción ${ }^{8}$.

Quizá la mejor manera de caracterizar aquello a lo que Peirce denomina abducción sea partir de uno de los ejemplos que da del mencionado procedimiento.

«(...) Por ejemplo, sé que el tipo de hombre conocido y clasificado como un Mugwump [persona independiente en política] posee ciertas características [enumeración de las características definitorias] (...) Son estas opiniones, entre otras, las que constituyen las señales visibles de un Mugwump. Ahora bien, supongamos que encuentro casualmente a un hombre en un ferrocarril, y que al empezar a conversar con él veo que mantiene opiniones de este tipo; naturalmente paso a suponer que es Mugwump. Esto es inferencia hipotética. Es decir, selecciono un cierto número de características fácilmente verificables de Mugwump, encuentro que este hombre las tiene, e infiero que tiene todas las demás que integran a un pensador de esta índole» (1892a: 271).

El procedimiento sugerido puede esquematizarse de la siguiente manera:

${ }^{8}$ La distinción entre abducción, inducción y analogía, si bien es analizada expresamente por Peirce, merece ser tratada en detalle teniendo en cuenta los distintos alcances con que suelen utilizarse actualmente esos términos. Esta tarea excedería el marco del trabajo, por lo que sólo haremos mención al criterio utilizado por el autor.

Respecto de la relación que guardan la abducción y la inducción sostiene que en ambos tipos de argumento se parte de la ausencia de conocimiento. Peirce asimila inducción y abducción, pues en ambas se intenta responder a la pregunta de «si ciertos objetos poseen ciertas características» (1868: 94). La diferencia está dada por lo siguiente: mientras en la inducción se desconoce si además de los objetos que se sabe poseen ciertas características existen otros que también las poseen, en la abducción en cambio se desconoce si además de las características que se sabe que poseen ciertos objetos los mismos tienen otras no implicadas por aquellas.

Por otra parte, respecto de la analogía, Peirce sostiene que es un argumento complejo que se compone de un momento inductivo y de un momento abductivo (1868: 62). Se parte de considerar objetos particulares. Se induce observando a uno de ellos que todos los objetos de su clase poseen ciertas características. Luego se constata que el otro objeto posee algunas características, por lo que mediante abducción se lo subsume en dicha clase. Luego mediante deducción se puede predicar de este último cualquier de las características definitorias de la clase. 
1. $(\mathrm{x})[\mathrm{MUGWUPx} \equiv(\mathrm{Rx} \cdot \mathrm{Sx} \cdot \mathrm{Tx} \cdot \mathrm{Qx})]\left[\right.$ Concepto conocido] ${ }^{9}$

2. $\mathrm{Ra}-\mathrm{Sa}$

[Enunciado fáctico sobre a]

3. MUGWUMPa

[Hipótesis. Subsunción individual] ${ }^{10}$.

4. Ta $\cdot \mathrm{Qa}$

[Deducción de 1 y 3]

Estamos en presencia de una operación a la que Peirce caracteriza como «una inducción a partir de cualidades» (1892a: 171). Ningún elemento que nos indique el origen de la hipótesis ni algún procedimiento para fijarla. Vemos cómo la misma nos permite explicar (subsumir en una clase que a su vez forma parte de la formulación de una ley conocida) al objeto «a» a los efectos de aumentar el conocimiento que sobre él poseíamos.

El paso de 1. y 2. a 3. no encuentra hasta el momento otra justificación más que en la decisión de quien analiza la cuestión, quien postula o conjetura una relación de subsunción que le permite explicar luego aquello que necesitaba de una explicación. Es evidente que si subsumiera los hechos o predicados conocidos en otro enunciado general diferiría la intelección que hiciera de los mismos. La abducción como procedimiento (si pretende dar cuenta de la tarea de descubrimiento) nos debería indicar los pasos a seguir antes de formular nuestras conjeturas, aunque más no sea para permitirnos reducir la posibilidad de error en las mismas.

En otro texto contempla la posibilidad de que se utilice la operación

${ }^{9}$ Utilizamos un bicondicional, pues consideramos que el enunciado general opera en el esquema con una definición del predicado P. Reconocemos, sin embargo, que el carácter suficiente y necesario de todas las características definitorias es uno de los puntos claves en la discusión, Eco (1984) se dedica detalladamente a esta cuestión. En el contexto en el que estamos trabajando no traerá mayores consecuencias no tomar en cuenta esta discusión, aunque sin lugar a dudas deberemos considerarla en futuros trabajos. La utilización del condicional material (más acorde con el sentido que puede tener la relación de significación en los lenguajes naturales y respecto de los denominados signos naturales -indicios, síntomas-) sólo afectaría la atribución de las otras características definitorias del predicado al objeto subsumido, las que no se derivarían deductivamente de la conjetura. No obstante, dado que por hipótesis se acepta la subsunción es evidente que con el mismo carácter se aceptan las notas características del predicado en cuestión, resultando irrelevante si las mismas pueden o no deducirse de la conjetura. Las relaciones más importantes, que son las que ligan el fenómeno sorprendente con todos aquellos enunciados en los que se utiliza el predicado en el que se lo ha subsumido, no se ven alteradas por la forma en que se simbolice la regla (ver infra).

${ }^{10}$ Para saber si el objeto b reúne otras características que las que se le conocen y exponen en 2., «la inferencia procede como si se conociesen todas las características requeridas a la determinación de un cierto objeto, o clase» (1868: 93). 
para determinar relaciones entre clases, esto es, a nivel genérico. El esquema sería el mismo, con la diferencia que no se necesitaría emplear constantes para hacer alusión a objetos determinados.

En este caso, «la función de la hipótesis es la de sustituir una gran serie de predicados, que en sí mismos no forman una unidad, por uno solo (o un pequeño número) que los implica a todos, junto (quizá) con un número indefinido de otros. Es, por tanto, también una reducción de una multiplicidad a una unidad» (1868: 96).

En este fragmento se contemplan dos posibles reconstrucciones de la abducción, en una la hipótesis cumple la función de sustituir una variedad de predicados que no forman una unidad por uno solo (o un pequeño número) que los implica a todos [A], en la otra se da el caso de que el predicado unificador implica además un número indefinido de otros predicados [B]. Esquematizaremos ambas posibilidades.

[A]

1. $P x$

2. Q

3. $\mathrm{Rx}$

4. $(\mathrm{x})$

[Predicados que no forman unidad]

$$
[(\mathrm{Px} \cdot \mathrm{Qx} \cdot \mathrm{Rx}) \equiv \mathrm{Bx}] \quad \text { [Hipótesis] }
$$

Esta caracterización difiere de las presentadas anteriormente en que no se hace hincapié en la atribución de propiedades a objetos (subsunción individual), sino en la llamada subsunción genérica, es decir de un predicado múltiple o complejo en otro predicado más simple equivalente en este caso. Opera en un plano estrictamente conceptual $^{11}$.

${ }^{11}$ «El proceso que conduce a la afirmación de que un predicado es verdadero de un cierto individuo, que implica que la propiedad designada por el predicado está ejemplificada en ese individuo o que el individuo pertenece a la clase que es la extensión del predicado en cuestión es tradicionalmente denominado en la jerga jurídica subsunción. Cabe subrayar que el problema de la subsunción no es un tema específicamente jurídico, sino un problema del uso empírico del lenguaje en general, esto es, de la aplicación de términos generales de un lenguaje a objetos particulares del mundo. En otras palabras, se trata del viejo problema filosófico de la relación entre palabras (generales) y cosas. Todo uso empírico del lenguaje entraña la existencia de ciertas reglas semánticas que especifican: a) qué objeto particular es referido por un nombre, b) qué atributo (propiedad o relación) es designado por un término general o predicado. (...) Por subsunción individual entendemos el problema de la determinación de la verdad de ciertos enunciados individuales contingentes (sintéticos) de la forma general «Fa», donde «F» representa un predicado del lenguaje $\mathrm{y}$ «a» es un nombre propio, esto es, el nombre de un objeto individual. Subsunción genérica es el problema de establecer qué relación se da entre dos predicados. (Alchourrón y Bulygin, 1989: 305-308-309). En este sentido, la abducción puede caracterizarse como el procedimiento que lleva a conjeturar una relación de subsunción a los efectos de mejorar el aparato conceptual o explicar fenómenos sorprendentes. 
[B] 1. Px

2. Qx

3. $\mathrm{Rx}$

4. $(\mathrm{x})$

5. $(\mathrm{x})$

[Predicados que no forman unidad]

$[(\mathrm{Px} \cdot \mathrm{Qx} \cdot \mathrm{Rx}) \equiv \mathrm{Bx}] \quad[$ Hipótesis $]$

$[\mathrm{Bx}->(\mathrm{Sx} \cdot \mathrm{Tx} \cdot \mathrm{Vx})] \quad$ [Enunciado hipotético]

Esta formulación abre la posibilidad de que el predicado unificador postulado en la hipótesis no cumpla sólo la función de dar coherencia o hacer inteligibles a los otros predicados unificándolos, sino que también permita derivar de la presencia de ellos la presencia de otros predicados merced a la utilización de otros enunciados generales que involucren al predicado unificador. Así, por ejemplo, en este caso podríamos saber, si constatamos que determinado objeto presenta las características $\mathrm{P}, \mathrm{Q}$ y $\mathrm{R}$, que el mismo presenta también las propiedades $\mathrm{S}, \mathrm{T}$ y $\mathrm{V}$ con sólo postular 4 como hipótesis, dándose por conocida 5.

\section{6. $\underline{\mathrm{Pa} \cdot \mathrm{Qa} \cdot \mathrm{Ra}}$ \\ [Conocimiento fáctico]}

7. $\mathrm{Sa} \cdot \mathrm{Ta} \cdot \mathrm{Va}$

[Deducción de 4, 5 y 6]

Esto pone de manifiesto el gran poder de elucidación que tiene el proceder a conjeturar una relación de este tipo, tanto sobre el aparato conceptual como sobre la aplicación del mismo para analizar los objetos de la realidad. Pero nada se dice aún sobre las vías a seguir para que la unificación postulada pueda considerarse correcta o al menos guiada.

Analizaremos textos posteriores a los efectos de hallar respuesta a este interrogante. En escritos posteriores, Peirce distingue de manera más clara abducción e inducción ${ }^{12}$.

Esta relación entre los conceptos «subsunción» y «abducción» plantea el problema (analizado por Eco) de los límites entre inferencia y significación, que implica a su vez determinar las incumbencias de la lógica (metodología) y la semiótica, al mismo tiempo que acerca a la discusión la problemática de la «interpretación» (de hechos o textos). Dado que para Peirce la lógica forma parte de la semiótica todo argumento es una especie particular de signo, lo que lo lleva a no plantearse el problema que hemos mencionado. Así por ejemplo utiliza como ejemplo de índex (uno de los tipos de signo que distingue) el siguiente caso: «Examinemos algunos ejemplos de índices (...) Veo a un hombre patizambo, con pantalones de pana, polainas y una chaqueta. Son probables indicaciones de que es un jockey, o algo por el estilo (1893/1902: 148-149). La similitud con los ejemplos que utiliza para ilustrar el proceso abductivo (1892a: 271) es evidente. Esta cuestión debe ser analizada antes de emitir una opinión final sobre la abducción.

${ }^{12}$ «La deducción prueba que algo tiene que ser: la inducción muestra que ago es actualmente operativo; la abducción sugiere meramente que algo puede ser» (1903b: 136). 
«La abducción es el proceso de formar una hipótesis explicativa. Es la única operación lógica que introduce alguna idea nueva (...)» (1903b: 136).

«La abducción arranca de los hechos, sin tener, al inicio, ninguna teoría particular a la vista, aunque está motivada por la sensación de que se necesita una teoría para explicar los hechos sorprendentes. (...) En la abducción, la consideración de los hechos sugiere la hipótesis. (7.218)» (Sebeok-Umiker-Sebeok, 1979: 47).

De la lectura de estos fragmentos surgen las siguientes características definitorias de la abducción: i) es el proceso de formar una hipótesis explicativa; ii) es la única operación lógica que introduce un nuevo conocimiento; iii) parte de los hechos con la sensación de que los mismos pueden explicarse mediante una teoría; iv) consiste en la búsqueda de esta teoría, la que es sugerida por la consideración de los hechos.

A la luz de esta caracterización debemos hallar en los textos de Peirce respuestas para las siguientes cuestiones: i) cuáles son esos pasos o procesos que llevan a la formación de una hipótesis; ii) de qué manera la búsqueda de la teoría es sugerida por los hechos.

\subsection{El problema de la caracterización}

Al encontrarnos con un fenómeno que, dada la circunstancia en la que nos hallamos, nos resulta problemático o sorprendente intentamos comúnmente explicarlo subsumiéndolo en enunciados que relacionan conceptos que nos son familiares o conocidos.

Para Peirce una persona en esta situación procede de la siguiente manera: examina las características del fenómeno sorprendente y «advierte algún carácter o relación especial entre ellas, que de inmediato reconoce como característico de un concepto que ya está almacenado en su mente, de manera que se avanza una teoría que explique (es decir, que haga necesario) lo que resulta sorprendente en el fenómeno. (2: 776)» (Harrowitz, 1983: 244).

Esta caracterización implica lo siguiente: i) que todo fenómeno puede ser analizado a partir de los caracteres que presenta y de las relaciones que entre ellos guardan; ii) que una consideración minuciosa de los mismos permite avanzar la hipótesis o teoría

En este fragmento parece referirse críticamente a su postura pasada cuando afirma que la «analogía entre hipótesis e inducción es tan grande que algunos lógicos las han confundido. La hipótesis ha sido llamada inducción de caracteres. (2.632)» (Sebeok-Umiker-Sebeo, 1979: 48) 
explicativa; iii) y que esto ocurre cuando reconocemos que esos caracteres concuerdan con ciertos caracteres definitorios de conceptos que almacenamos comúnmente en nuestra mente, lo que permite conjeturar la subsunción del fenómeno sorprendente en dicho concepto.

La abducción como procedimiento podría reconstruirse entonces de la siguiente manera:

1. Se aíslan todos los caracteres presentes en el fenómeno sorprendente o problemático.

2. Se busca un concepto que reúna todos esos caracteres definitorios.

3. Se utiliza un enunciado que relacione el mencionado concepto con otros para explicar el fenómeno sorprendente, haciéndolo de esta manera inteligible desde nuestro marco teórico.

Esta reconstrucción continúa la línea trazada cuando sostuvimos que en Peirce la abducción consistía en plantear la explicación de un objeto o clase determinados subsumiéndolos en una clase que a su vez está relacionada con otras mediante un enunciado general. A su vez avanza en la caracterización del procedimiento que debe seguirse para llevar a cabo con éxito dicha subsunción. También pone de manifiesto la estrecha relación que existe en esta etapa entre explicar un fenómeno sorprendente y sostener que ciertos elementos significan o representan otros, lo que nos lleva nuevamente a justificar el tratamiento de la cuestión desde el punto de vista semiótico.

No obstante esta reconstrucción trae aparejado un grave inconveniente. El planteo presupone que podemos aislar todos los caracteres relevantes de un fenómeno complejo, lo que es rechazado aún por el propio Peirce.

En efecto, Peirce sostiene que en la abducción «un número de caracteres pertenecientes a un tipo determinado se encuentra en un objeto dado; de lo que se infiere que todos los caracteres de ese tipo pertenecen al objeto en cuestión», pero al mismo tiempo reconoce que «los caracteres no son susceptibles de una simple enumeración como los objetos» y que los mismos «se agrupan en categorías», por lo que «cuando formulamos una hipótesis (...) examinamos sólo una sola serie de caracteres, o tal vez dos o tres, y no tomamos ningún espécimen de las otras series (2.632)» (Sebeok-Umiker-Sebeok, 1979: 48).

También aclara que para una serie definida de características «hay, tal vez, un millón de otras maneras posibles de explicarlas, sólo que todas son, desgraciadamente, falsas (Ms, 692)» (Sebeok-Umiker-Sebeok, 1979: 37-38). 
El procedimiento debe entonces reconstruirse de la siguiente manera:

1. Se toma una serie (o series) de caracteres presentes en el fenómeno sorprendente o problemático.

2. Se lo subsume en aquel concepto que reúna esos caracteres entre sus elementos definitorios.

3. Se utilizan los enunciados que relacionen el mencionado concepto con otros para explicar el fenómeno sorprendente, haciéndolo de esta manera inteligible desde nuestro marco teórico.

4. La selección, cuando tenemos más de una alternativa disponible, se lleva a cabo rechazando aquellas explicaciones altamente improbables y entre hipótesis equiprobables acudiendo a la contrastación empírica a los efectos de determinar cuál de todas es verdadera.

Seguimos sin poder determinar los criterios para elegir la serie de caracteres entre las infinitas series que se nos plantean como opción, así como el procedimiento para escoger el concepto a utilizar para llevar a cabo la subsunción cuando en más de uno encontramos las características del objeto sorprendente. Veremos las respuestas de Peirce a estos interrogantes en el próximo apartado.

\subsection{El problema del fundamento}

Peirce analiza el fundamento de la operación descripta en el apartado anterior de distintas maneras: i) haciendo referencia a la historia de la ciencia, en la que puede constatarse su utilización ${ }^{13}$; ii) sosteniendo

${ }^{13}$ «Un hombre tiene que estar categóricamente loco para negar que la ciencia ha hecho muchos descubrimientos verdaderos. Pero cada uno de los ítems particulares de la teoría científica que hoy se encuentran asentados lo deben a la abducción. (...) Pero, ¿cómo es que toda esta verdad ha llegado a alumbrarse por un proceso en el que no hay compulsividad alguna, ni tendencia hacia la compulsividad? ¿Ha sido por azar? Consideremos la multitud de teorías que pueden haberse sugerido. Un físico, en su laboratorio, da con algún fenómeno nuevo. ¿Cómo sabe que las conjunciones de los planetas no tienen nada que ver con ello, o que no es quizá porque a la emperatriz viuda de China se le haya ocurrido por la misma época, hace un año, pronunciar alguna palabra con poder místico, o porque se encuentra presente algún genio invisible? Pensemos en los trillones de trillones de hipótesis que pueden hacerse, de las cuales sólo una es verdadera; y, con todo, el físico, después de dos o tres conjeturas, o, todo lo más, de una docena, da muy cerca de la hipótesis correcta. Por azar no lo hubiese conseguido, probablemente ni en todo el tiempo transcurrido desde que la tierra se solidificó. Pueden ustedes decirme que al principio se recurrió 
que la operación no es más que la suma de intentos de adivinación ${ }^{14}$; iii) sosteniendo que para justificarla sólo es necesario que explique el hecho observado ${ }^{15}$; iv) en la misma línea que la explicación anterior, una abducción se justifica cuando mediante inducción comprobamos la verdad de la hipótesis ${ }^{16}$; v) y finalmente, sosteniendo que la abducción es posible, pues el hombre posee un cierto insight de los elementos generales de la naturaleza, lo que hace comparable la operación con los instintos ${ }^{17}$.

a hipótesis astrológicas y mágicas, y que sólo gradualmente hemos aprendido ciertas leyes generales de la naturaleza, a consecuencia de las cuales el físico busca la explicación de su fenómeno dentro de las cuatro paredes de su laboratorio. Pero si ustedes observan la cuestión más determinante, verán que por esta vía no puede explicarse la cuestión a un cierto nivel importante. Tomemos una perspectiva amplia de la cuestión. Durante más de veinte mil años o así, el hombre no se ha ocupado de problemas científicos. Pero, si quieren, pongamos diez veces esto. Pero esto no es ni una cienmilésima parte del tiempo que puede considerarse que ha estado buscando su primera teoría científica (...) Ustedes pueden elaborar esta o aquella explicación psicológica de la cuestión. Pero permítanme decirles que toda la psicología del mundo junta no sacará el problema lógico justo de donde estaba» (Peirce, 1903b: 137-138).

${ }_{14}$ «Un objeto dado presenta una combinación extraordinaria de características de las que nos gustaría tener una explicación. Que exista alguna explicación de ellas es una mera suposición; y, de existir, lo que las explica es algún hecho oculto: mientras que hay, tal vez, un millón de otras maneras posibles de explicarlas, sólo que todas son, desgraciadamente, falsas. En una calle de Nueva York, se descubre un hombre apuñalado por la espalda. El jefe de la policía podría abrir el censo de los habitantes, poner el dedo sobre un nombre cualquiera y conjeturar que es el asesino. ¿Qué valor tendría una conjetura semejante? Sin embargo. el número de nombres en una lista así no es nada comparado con la multitud de posibles leyes de atracción que podrían haber justificado la ley del movimiento planetario de Kepler [sic] y que, previamente a la verificación mediante constataciones de perturbaciones, etc., las hubiera explicado perfectamente. Newton, me diréis, supuso que la ley tenía que ser simple. Pero, ¿qué era eso sino amontonar un intento de adivinar sobre otro? Sin duda, en la naturaleza hay muchos más fenómenos complejos que simples. No hay justificación para lo que no sea poner [una abducción] como interrogación. (Ms. 692)» (Sebeok-Umiker-Sebeok, 1979: 37-38).

15 «(...) una conclusión retroductiva sólo justificada si explica un hecho observado. Una explicación es un silogismo cuya premisa mayor, o regla, es una ley o regla conocida de la naturaleza u otra verdad general; la premisa menor, o caso, es la hipótesis o conclusión retroductiva, y la conclusión, o resultado. es el hecho observado (o establecido de otra manera). (1: 89)» (Harrowitz, 1983: 243).

${ }^{16}$ Su única justificación [de la abducción] es la de que a partir de su sugerencia la deducción puede extraer una predicción que puede comprobarse mediante inducción, y que, si podemos llegar a aprender algo o a entender en absoluto los fenómenos, esto tiene que conseguirse mediante la abducción. Por lo que puedo saber, no puede darse ninguna razón cualquiera que sea a favor de la misma; y no necesita razón alguna, ya que sólo ofrece sugerencias» (Peirce, 1903b: 137).

${ }_{17}$ «Sea cual sea el modo como el hombre ha adquirido su facultad de adivinar las vías de la naturaleza, lo cierto es que no ha sido mediante una lógica autocontrolada 
Ninguna de estas explicaciones resulta satisfactoria. Así de nada nos sirve para aumentar nuestro conocimiento sobre la abducción el hecho de postular su utilización en todo descubrimiento científico de envergadura. Peor aún son los otros intentos, pues si es cierto que las hipótesis no surgen más que por adivinación o instinto no puede sostenerse al mismo tiempo la posibilidad de reconstruir lógicamente la operación. De la misma manera sostener que la única justificación posible se da una vez enunciada la hipótesis significa reconocer que nada puede decirse sobre su formación, lo cual contradice palmariamente la caracterización hecha de la abducción en un primer momento.

Estas contradicciones pueden resolverse de distinta manera: i) rechazando la posibilidad de hablar de un procedimiento denominado abducción reconstruible con provecho en el campo metodológico; ii) tratando de explorar las sugerencias de Peirce de manera tal que las contradicciones desaparezcan, lo que debe realizarse desde un planteo superador de sus limitaciones.

Antes de poder abrazar la alternativa i) creemos necesario analizar las principales propuestas que optaron por la otra vía, es decir que intentaron continuar con la idea de la abducción superando al mismo tiempo los problemas que encontraba en Peirce.

Los problemas no resueltos por Peirce, pero que deben ser resueltos si se quiere defender a la abducción como método son los siguientes: i) determinar los criterios que deben guiar la selección de los caracteres que se considerarán relevantes en el fenómeno a explicar;

y crítica. Ni siquiera ahora puede dar ninguna razón exacta de sus mejores conjeturas. Me parece que el enunciado más claro que podemos hacer de la situación lógica -la más libre de toda mezcla cuestionable- es decir, que el hombre tiene un cierto discernimiento [insight] de la terceridad, de los elementos generales de la naturaleza, no lo bastante fuerte como para no estar abrumadoramente con más frecuencia equivocado que acertado. Lo llamo discernimiento porque hay que referirlo a la misma clase general de operaciones a la que pertenecen los juicios perceptivos. Esta facultad participa a la vez de la naturaleza general del instinto, pareciéndose a los instintos de los animales en que supera con mucho los poderes generales de nuestra razón y en que nos dirige como si estuviésemos en posesión de hechos que se encuentran por completo más allá del alcance de nuestros sentidos. Se parece también al instinto en su pequeña predisposición al error; pues aunque yerra con más frecuencia que acierta, con todo la frecuencia relativa con la que acierta es en conjunto la cosa más maravillosa de nuestra constitución. Si ustedes preguntan a un investigador por qué no prueba esta o aquella disparatada teoría, dirá, «no parece razonable». Es curioso que raramente utilizamos esta palabra cuando se ve con claridad la lógica estricta de nuestro procedimiento. No decimos que un error matemático no es razonable. Llamamos razonable aquella opinión cuyo único apoyo es el instinto(...)». (Peirce, 1903b: 138). 
ii) explicar los mecanismos que permiten controlar la subsunción de los mismos en conceptos conocidos; iii) explicitar los procedimientos de selección de los conceptos a tener en cuenta antes de llevar a cabo la mencionada subsunción.

En busca de soluciones para estas cuestiones acudiremos al planteo de Norwood Hanson quien sostuvo, en la segunda mitad de este siglo, que continuar las líneas sugeridas por Peirce podía ser de alguna utilidad para la filosofía de la ciencia.

\section{La retroducción en la obra de $\operatorname{Hanson}^{18}$}

Norwood Russell Hanson (1924-67) en su libro Patrones de descubrimiento (1958) sostiene que el enfoque hipotético-deductivista, si bien es superior al inductivista, no es del todo satisfactorio, pues no da cuenta del procedimiento de creación o descubrimiento de las hipótesis. Luego de criticar los aspectos que considera incorrectos de las mencionadas teorías, construye una propuesta que él mismo caracteriza como continuadora del planteo de Peirce. La misma defiende la tesis de que existe un procedimiento que no es ni inductivo ni deductivo que permite dar cuenta de cómo surgen las teorías: la retroducción.

Hanson resalta el acento conceptual de la operación. Desde que se detectan ciertas anomalías a partir del marco de referencia, se procede a buscar la premisa que permita hacer inteligibles dichos datos.

Esto se logra operando desde el marco de referencia, es decir, subsumiendo los fenómenos en conceptos conocidos que a su vez permitan ligarlos inferencialmente con fenómenos normales; o bien operando sobre el marco de referencia, postulando nuevos conceptos (también se pueden redefinir los conceptos conocidos) que sistematicen las observaciones integrándolas al modelo ${ }^{19}$.

El marco de referencia delimita un ámbito de conjeturas plausibles, el que puede ir acotándose mediante la formulación de «protohipótesis», dentro del cual probablemente estará la solución que buscamos.

${ }^{18}$ Tomaremos como base para la exposición los textos de Hanson (1958) y (1971).

19 «Muchas soluciones significativas a problemas científicos han sido generadas por medio de recursos racionalmente dirigidos a entidades 'como si', entidades teóricas, cuya necesidad intelectual ha proporcionado ocasión práctica para que los experimentadores buscasen después tales denotata dentro de la materia». (1971: 54). El rol de estas entidades teóricas es «sistematizar y estructurar conjuntos de oraciones observacionales dentro de una disciplina» (1971: 57-58). 
La tarea de búsqueda está guiada por criterios de racionalidad que deben ser objeto de indagación filosófica, los que no puede reducirse de ninguna manera a cuestiones meramente psicológicas ${ }^{20}$.

\subsection{La forma de la retroducción}

El problema ahora es mostrar cómo opera el procedimiento reproductivo, cuáles son los criterios de racionalidad que se emplean y cómo se construyen los ámbitos de plausibilidad, en una palabra, cuáles son los pasos que llevan a la formulación de una hipótesis aceptable. La verdad o falsedad de la misma es una cuestión a resolver posteriormente mediante la deducción de predicciones y la realización de experimentos, la pregunta que debe contestar Hanson es ¿cuál es el procedimiento que permite escoger como aceptables sólo unas pocas conjeturas entre las infinitas que podrían postularse como respuesta a una misma cuestión?

Transcribiremos el único fragmento en el que Hanson ofrece un esquema del proceso retroductivo:

«La forma de la inferencia es ésta:

1. Se observa cierto fenómeno sorprendente P.

2. P sería explicable si $\mathrm{H}$ fuera cierta.

3. Por tanto, hay razones para pensar que $\mathrm{H}$ es cierta».

«H no puede ser inferida retroductivamente hasta que su contenido se despliegue en 2 (...) Las $\mathrm{H}$ no se desprenden aquí de un procesamiento actuarial o estadístico de un número grande de casos $\mathrm{P}$. Tampoco son simples «ideadas» y los $\mathrm{P}$ deducibles de ellas» (1958: 185).

El hecho de que la hipótesis «explique claramente» los fenómenos en cuestión es la base para inferir retroductivamente que es razonable sostenerla.

${ }^{20}$ «iSe pueden resolver razonablemente los problemas dentro de la investigación científica? Por descontado. En esa medida existen cánones para la razón, criterios de racionalidad, que distinguen la buena técnica de la mala, las conjeturas prometedoras de las dudosas, las direcciones de investigación que prometen de los cursos de investigación con pocas perspectivas. Tales criterios, o estrategias, podrían muy bien ser examinados por los filósofos de la ciencia en términos que no se «reducen» a una mera especulación psicológica (...). El examen de las estrategias racionales de la resolución científica de problemas, por tanto, no se reduce a ser una reconstrucción lógica o un recital psico-factual. Es, en principio, una investigación filosófica de un tipo diferente» (1971: 53). 
El mismo Hanson reconoce que la hipótesis o teoría no puede ser inferida retroductivamente «hasta que su contenido se despliegue en 2 », esto es, hasta que quede establecido que «explica claramente» las anomalías de las que partió.

Esta presentación es altamente problemática, pues el requisito para que opere la retroducción parece ser la formulación de la hipótesis y la constatación de que la misma cumple la única condición de explicar claramente los fenómenos sorprendentes. Esto parece reducir la retroducción a la aceptación de una hipótesis que ya ha pasado ciertos procedimientos de contraste que demostraron su plausibilidad, lo que obliga a considerar que la misma no puede constituir el procedimiento para sugerir una hipótesis como pretende Hanson.

La afirmación que las hipótesis no pueden ser «simples ideadas» no encuentra a simple vista argumentos que la apoyen en este fragmento.

Para rescatar el planteo de Hanson debemos preguntarnos por aquello a lo que este autor considera una «explicación», pues esta es la piedra de toque de su reconstrucción.

«Los enunciados de las leyes dinámicas ayudan a explicar los sucesos físicos. Un suceso queda explicado cuando se le puede reducir a otros sucesos que requieran menos explicación; cuando se muestra que forma parte de una estructura inteligible de sucesos». (Hanson, 1958: 195). «Explicar las perplejidades exige ligarlas con casos normales, con lo no sorprendente. Lo inusual sólo deja de ser sorprendente cuando se conecta inferencialmente con lo usual. Los modelos nos sugieren ámbitos de explicaciones posibles y rutas hacia lo no sorprendente. (...) El conocimiento pleno de una cosa consiste en esperar cada rasgo de esa cosa 'como cosa natural'» (Hanson, 1971: 61).

De estos fragmentos surge claramente que «explicar» significa reducir el fenómeno sorprendente a conceptos conocidos en el marco de un modelo aceptado, lo que permite conectarlo inferencialmente con casos normales. En última instancia, lo que Hanson reclama es la inserción del fenómeno en un modelo que lo haga inteligible. La «reducción» a la que hace referencia es totalmente asimilable al concepto de «subsunción» que utilizamos para reconstruir la propuesta de Peirce.

Hanson requiere además que la hipótesis «explique claramente» el fenómeno sorprendente, como diría Peirce, que lo explique «como cosa natural».

¿Cuáles son los requisitos que debe reunir una hipótesis para considerar que «explica claramente» y «como cosa natural» determinado fenómeno? 
Hanson no abunda en el tema, sólo hace dos menciones respecto a la cuestión: i) en la primera sostiene que «para que un fenómeno x sea 'explicable de modo natural' es fundamental la percepción de la estructura completa en la que está inmerso» (1958: 185), esto significa que debemos tomar en cuenta todas las características del fenómeno (hasta los detalles) para determinar si la hipótesis es aceptable; ii) el fenómeno a explicar y la hipótesis que se postule: «deben tener propiedades lógicas adicionales a fin de figurar en F sería explicable de un modo natural si $\mathrm{H}$ fuese cierta». Si entendemos que $\mathrm{H}$ va a explicar $\mathrm{F}$, entonces $\mathrm{H}$ no puede descansar sobre los rasgos de $\mathrm{F}$ que requieren explicación (...)» (1958: 186). El presupuesto general de ambas condiciones es trabajar a partir de un marco de referencia que es lo que determina en última instancia el ámbito de conjeturas plausibles.

\subsection{La retroducción en la historia de la ciencia}

Como vimos, gran parte de la estrategia argumentativa de Hanson consiste en mostrar la necesidad de la retroducción para explicar ciertos aspectos de la tarea de investigación porque los mismos no son reflejados en los enfoques hipotético-deductivos e inductivos.

Otro campo en el que Hanson encuentra elementos para sustentar su postura es la historia de la ciencia, así plantea ciertos casos paradigmáticos para mostrar que los otros enfoques no pueden dar cuenta de ellos, mientras que aceptando la retroducción como operación autónoma se los explica sin necesidad de forzar su presentación.

\subsubsection{Galileo}

«Baste decir que Galileo siempre trató de explicar sus datos originales mediante la construcción de hipótesis generales y teorías a su 'imagen'. Sus hipótesis no son nunca compendios inductivos de sus datos; tampoco las puso en duda hasta que pudo deducir nuevas sentencias observacionales que se comprobaron experimentalmente. Galileo supo que sus trabajos habían tenido éxito cuando la hipótesis de la aceleración constante fue capaz de estructurar los diversos fenómenos en que había ido fijando su atención durante treinta años. Su razonamiento avanzaba de comprensión en comprensión culminando en un explicans físico final. Las deducciones posteriores fueron meramente confirmativas» (1958: 188).

Con este ejemplo se pone de manifiesto cómo puede ser considerada exitosa una teoría antes de su configuración, bajo la única condición 
de que haga inteligible los fenómenos sorprendentes, insertándolos en el marco teórico de manera coherente y significativa.

«Galileo no busca una fórmula descriptiva; tampoco trata de predecir observaciones acerca de los cuerpos en caída libre. Él ya tiene una fórmula. Sabe que los espacios recorridos en tiempos iguales están en la misma relación que la serie de los números impares. Sabe que la distancia que recorre el cuerpo en su caída es proporcional al cuadrado del tiempo transcurrido. Busca más: una explicación de estos datos, los cuales deben ser sistematizados inteligiblemente» (1958: 121).

Para lograr esto, Galileo debió acuñar el concepto de aceleración constante, incluyendo las coordenadas temporales en su construcción, lo que hubiera tenido muy poco significado para los filósofos naturales que lo precedieron, «tan poco como lo hubiera tenido una coordenada 'fragancia' o una coordenada 'belleza'. Galileo rompe estas limitaciones conceptuales (...)» (1958: 124). Esto constituye un ejemplo de la postulación de entidades teóricas a las que Hanson aludió como producto de la retroducción.

Este ejemplo resalta el carácter conceptual de la operación, distinguiendo dos posibles formas de operar: i) dentro del marco de referencia, esto es, subsumiendo el fenómeno sorprendente en conceptos conocidos, lo que permite ligarlo inferencialmente con casos normales; ii) sobre el marco de referencia, es decir, postulando nuevos conceptos en dicho marco que permitan sistematizar los enunciados observacionales sorprendentes ${ }^{21}$. Esto pone en evidencia la importancia que tiene el marco de referencia como ámbito de plausibilidad de nuestras conjeturas, por lo que una modificación en el mismo puede llevar a cambiar la intelección que hagamos de los fenómenos que observamos ${ }^{22}$, y al mismo tiempo a ampliar los límites dentro de los que podemos postular hipótesis aceptables.

Podemos apreciar cierta similitud entre estas dos operaciones y las dos versiones de abducción que reconstruimos a partir de los escritos de Peirce (ver supra, págs. 23-24).

${ }^{21}$ «Los triunfos de la física contemporánea consisten en descubrir que un parámetro puede ser considerado como una función de algún otro. La relación física 'real' entre ellos puede no ser evidente o incluso inexistente» (1958: 188).

22 «Las afirmaciones relativas al modelo son diferentes de las afirmaciones acerca de los detalles. No son resúmenes inductivos de afirmaciones relativas a los detalles (...) si las afirmaciones relativas a los detalles son empíricas, también lo son -aunque no en la misma forma- las frases relativas al modelo que proporciona sentido a las anteriores. Negar una frase relativa al detalle es hacer algo dentro del modelo. Negar una frase relativa al modelo es atacar al sistema conceptual mismo, y esta negación no puede operar del mismo modo» (1958: 186). 


\subsubsection{Kepler}

El otro ejemplo (al que le dedica 16 páginas de su libro) es el descubrimiento de Kepler de que la órbita de Marte seguía la forma de una elipsis.

«Kepler no empezó con la hipótesis de que la órbita de Marte era elíptica para deducir a continuación enunciados confirmados por las observaciones de Brahe. Estas últimas observaciones le fueron dadas, y plantearon el problema, fueron el punto de partida de Johannes Kepler. A partir de éstas se esforzó por obtener una hipótesis apropiada, después pasó a otra y después a otra, para acabar finalmente en la hipótesis de la órbita elíptica (...). El filósofo de la ciencia no debería ignorar lo que Peirce llama la retroducción más bella que se haya hecho jamás» (1958: 166).

No podemos transcribir todo el desarrollo del ejemplo por su extensión, pero el segmento escogido es una breve y adecuada descripción del caso.

A lo largo del mismo, Hanson explica cómo Kepler probó varias alternativas (algunas relativas a la forma de la trayectoria del planeta y otras respecto a las técnicas de medición que empleaba) y las fue desechando, pues no podía dar cuenta con las mismas de los datos recogidos por Tycho Brahe. Dado que la figura que buscaba debía encontrarse entre el círculo y el ovoide (ambas hipótesis refutadas por los datos de Brahe) conjeturó que debía tratarse de una elipse. No obstante la misma no explicaba todos los datos del explicandum. Finalmente se percató que lo que impedía esto era un error aritmético. «El tropiezo aritmético fue descubierto rápidamente, y este descubrimiento condujo a la total confirmación de la hipótesis» (1958: 180). Con esta conjetura pudo dar cuenta de todos los datos observacionales que constituyeron el punto de partida de su investigación.

Los elementos que Hanson considera relevantes del procedimiento de Kepler son: i) el explicandum ya era conocido por Kepler (eran las observaciones de Brahe); ii) el explicans no se obtuvo «razonando a partir de la hipótesis generales de las que dedujo consecuencias particulares» contrastables por la observación (1958: 182); iii) todas las reformulaciones de sus hipótesis Kepler las hizo con razones fundadas, no de manera caprichosa (1958: 182). Por todo esto, Hanson considera que el ejemplo de la tarea de Kepler tal como el mismo la detalla «es la obra máxima del razonamiento retroductivo» (1958: 182).

En él se pone de manifiesto el rol de las «protohipótesis», las que hasta ese momento sólo habían sido nombradas sin una adecuada caracterización. Las «protohipótesis» construidas estaban condicionadas por la necesidad de dar cuenta de todos los datos con que se contaba (las observaciones de Brahe) y por los límites impuestos por 
las conjeturas anteriores, lo que hace que cada uno de los pasos que llevaron a Kepler a la formulación de su hipótesis haya sido dado de manera razonada. Por último, vuelve a quedar en evidencia que la retroducción opera a nivel conceptual, dándose por concluida una vez que logra integrar al marco de referencia los datos de los que partió. Esto se logra estableciendo relaciones conceptuales intrasistemáticas (subsunción) o bien reformulando algunos elementos del marco de referencia. En este caso se dan ambas operaciones, pues se subsumen los datos recogidos al concepto de «elipsis» ya conocido y luego deben corregirse algunos cálculos aritméticos erróneos, lo que hace posible insertar los mencionados datos en un modelo coherente que los hace inteligibles.

\subsection{Balance}

La explicación de Hanson resulta un avance respecto de la formulación de Peirce en los siguientes aspectos: i) resalta el hecho de que la retroducción se maneja en un nivel conceptual y muestra las variantes con que puede operar; ii) señala la importancia del marco de referencia que guía la observación, el que juega un rol determinante en la consideración de aquello que consideraremos sorprendente (anomalía) y de los caracteres que consideraremos relevantes en el mismo a los efectos de formular una hipótesis explicativa; iii) enuncia algunas condiciones que debe reunir una hipótesis para ser aceptable, lo que puede tomarse como una guía para su formulación; iv) resalta la función del marco teórico como ámbito de conjeturas plausibles, el que puede acotarse mediante «protohipótesis»; v) ilustra con ejemplos tomados de la historia de la ciencia la plausibilidad de su planteo.

A su vez presenta los siguientes problemas: i) no establece cuáles son los supuestos criterios de racionalidad que guían la tarea de descubrimiento; ii) no reconstruye satisfactoriamente el procedimiento retroductivo, el que según su esquema (similar al que utiliza Schuster al analizar la cuestión (ver supra) puede ser cuestionado por: a) carecer de diferencias con el planteo hipotético-deductivo que pretende superar, o bien por, b) renunciar a la pretensión de dar cuenta del proceso de formación de hipótesis, pues la misma ya se encuentra formulada cuando supuestamente se produce la retroducción; iii) no queda claro en que se diferencia una hipótesis explicativa de una protohipótesis, y en caso de aceptarse la distinción, no se explica el proceso que lleva a su formulación de estas últimas.

Siguen en pie la mayoría de los problemas no resueltos por Peirce, que según dijimos debían resolverse si se quería defender a 
la abducción como método. Todavía no encuentran una solución satisfactoria las siguientes cuestiones: i) la determinación de los criterios que deben guiar la selección de los caracteres que se considerarán relevantes en el fenómeno a explicar; ii) la explicitación de los mecanismos que permiten controlar la subsunción de los mismos en conceptos conocidos; iii) la formulación de los procedimientos de selección (o creación) de los conceptos a tener en cuenta antes de llevar a cabo la mencionada subsunción.

Se debe buscar respuesta a estas cuestiones si se quiere contar con un procedimiento aceptable en el terreno de la formulación de hipótesis, de lo contrario seguiremos postulando la existencia indudable de algo que en el fondo no sabemos muy bien en qué consiste.

\section{El descubrimiento científico en Popper $^{23}$}

Nuestra intención con este apartado es mostrar que muchos de los argumentos que Hanson utilizó para criticar los modelos H-D y para justificar la necesidad del enfoque retroductivo, no son aplicables a todos los autores que defienden ese tipo de posiciones. Hanson parte de una reconstrucción de las posiciones hipotético-deductivas realizada a partir de la pregunta: «¿Cómo se organizan las teorías científicas?», lo que lleva a mostrar una posición respecto del descubrimiento científico demasiado rígida y pobre. Consultaremos los textos de Popper $^{24}$, pero tratando de contestar con los mismos a la siguiente cuestión: «¿Cómo se explica científicamente un fenómeno sorprendente?». De esta manera podremos comparar las respuestas para verificar si la diferencia entre las posiciones es tan grande como pareciera surgir de la exposición de Hanson.

\section{1. La explicación como objetivo de la ciencia}

Para Popper, el objetivo de la ciencia «es encontrar explicaciones satisfactorias de cualquier cosa que nos parezca a nosotros que necesita explicación» (1956: 172). Las teorías científicas son

${ }^{23}$ Tomaremos como base para la exposición los textos de Popper (1934), (1956), (1957), (1963) y (1972).

${ }^{24}$ Nosotros tomaremos como punto de comparación solamente esta postura, pues como Hanson habla en general de los enfoques hipotético-deductivistas, sus afirmaciones tienen que valer frente un reconocido representante de dicha tradición como lo es Popper. 
importantes porque nos ayudan a interpretar o explicar nuestras experiencias ${ }^{25}$. Las predicciones que de ellas pueden derivarse también lo son, pero sólo como instrumento de búsqueda de teorías verdaderas ${ }^{26}$.

Una explicación consiste en un conjunto de enunciados en el que unos describen el estado de cosas a explicar (explicandum) mientras que los otros forman la explicación en sentido estricto de la palabra (explicans).

La mayoría de las veces se parte de un hecho que no puede ser explicado dentro del marco de referencia que guía la tarea de observación, esto es de una anomalía ${ }^{27}$, para buscar luego las hipótesis que permitan dar cuenta del mismo. Dada la amplitud con que se señaló el objetivo de la ciencia, la tarea de investigación puede dirigirse también a hallar explicaciones para explicans ya aceptados (1956: 175).

Se parte de un explicandum conocido, mientras que el explicans (objeto de la investigación) debe por lo general ser descubierto. «Así la explicación científica, siempre que sea un descubrimiento, será la explicación de lo conocido por lo desconocido» (1956: 176) (1957: 91).

\subsection{La búsqueda del explicans}

Dado que el objetivo de la ciencia es explicar satisfactoriamente cualquier cosa que necesite explicación. ¿Cómo es el procedimiento por el cual el científico explica los hechos o los explicans?

Para Popper, el científico propone o conjetura esos explicans, y

${ }^{25}$ «Las teorías (...) nos ayudan a interpretar nuestras experiencias. (...) Constantemente interpretamos nuestra experiencia con ayuda de teorías. Un mal sabor o mal olor se interpreta como causados por un huevo podrido; y un patinazo -un término completamente teórico- explica o interpreta un movimiento inusual y peligroso de un coche como debido a una insuficiente fricción entre los neumáticos y la carretera» (1956: 156).

${ }^{26} \ll(\ldots)$ Para el teórico, las predicciones son importantes casi exclusivamente por su relación con la teoría; porque él está interesado en la búsqueda de teorías verdaderas y porque las predicciones pueden servir como contrastaciones y proporcionar una oportunidad para la eliminación de teorías falsas» (1956: 157).

${ }^{27}$ «Es muy cierto que cualquier hipótesis particular que elijamos habrá sido precedida por observaciones; por ejemplo, las observaciones que trata de explicar. Pero estas observaciones, a su vez, presuponen la adopción de un marco de referencia, un marco de expectativas, un marco de teoría. Si las observaciones eran significativas, si creaban la necesidad de una explicación y, así, dieron origen a la invención de una hipótesis, era porque no se las podía explicar dentro del viejo armazón teórico, del viejo horizonte de expectativas» (1957: 73). 
luego los somete a un proceso de contrastación a los efectos de evaluar si constituyen o no una explicación satisfactoria. «Una vez presentada a título provisional una nueva idea, aún no justificada en absoluto -sea una anticipación, una hipótesis, un sistema teórico o lo que se quiera-, se extraen conclusiones de ella por medio de que una deducción lógicas (tales como equivalencia, deductibilidad, compatibilidad o incompatibilidad, etc.), que existan entre ellas» (1934: 32).

Popper es tajante con relación a la posibilidad de dar cuenta del proceso que lleva a la adopción de una conjetura: «La etapa inicial, el acto de concebir o inventar una teoría, no me parece que exija un análisis lógico ni que sea susceptible de él. (...) No existe en absoluto un método lógico de tener nuevas ideas, ni una reconstrucción lógica de este proceso» (1934: 31-32). Habla veces de adivinación (1934: 259) e ingenio (1972: 189) para referirse al poder de sugerir nuevos explicans, otras veces de «instintos científicos» (1934: 73), considera que ese proceso sólo puede ser un interesante tema de análisis de la psicología, no de la filosofía de la ciencia. En una sola oportunidad menciona que la experiencia de contrastaciones previas por parte del científico puede influir en la adopción de futuras conjeturas que intenten explicar el mismo fenómeno, pero no vuelve a tocar el tema en ningún otro de los escritos consultados» (1934: 73).

Analicemos entonces el procedimiento que se utiliza para «contrastar críticamente las teorías y escogerlas, teniendo en cuenta los resultados obtenidos en su contraste», dado que es el único aspecto que admite una reconstrucción lógica según Popper.

\subsection{Los explicans satisfactorios}

Resumiendo podemos decir que para Popper una conjetura puede aceptarse como una explicación satisfactoria de ciertos hechos o teorías si cumple con las siguientes condiciones: i) de la misma se debe deducir el explicandum; ii) no debe ser falsa de manera evidente, esto es, debe ser razonable o plausible sostenerla aunque luego se demuestre que es falsa; iii) debe permitir derivar otras consecuencias contrastables diferentes del explicandum $^{28}$; iv) no debe entrar en contradicción con otros enunciados del sistema de referencia; v) debe tener contenido empírico; vi) en caso de estar en pugna con otra teoría similar

${ }^{28}$ «El explicans, para ser satisfactorio (...), debe satisfacer una serie de condiciones. En primer lugar, debe entrañar lógicamente al explicandum. En segundo lugar, el explicans tiene que ser verdadero, aunque, en general, no se sabrá que es verdadero; en cualquier caso, no debe saberse que es falso, ni siquiera después del examen más crítico». 
debe constituir comparativamente un adelanto científico; vii) debe ser capaz de superar el contraste empírico de sus predicciones ${ }^{29}$.

El procedimiento de contrastación resulta ser en todos los casos deductivo. La derivación de predicciones a los efectos de testar experimentalmente la conjetura no resulta ser ni la primera ni la única prueba por la que debe pasar para ser aceptada. No obstante, es de fundamental importancia, pues constituye la consumación de la propuesta central del criterio de demarcación adoptado por Popper: «(...) el criterio para establecer el status científico de una teoría es su refutabilidad o su testabilidad» (1957: 61).

Muchos filósofos de la ciencia, en parte justificadamente dada la importancia que Popper le asigna al problema de la demarcación, centran la exposición del método hipotético-deductivo en esta etapa de búsqueda de la refutación de las conjeturas. Esto da como resultado un esquema en el que el punto de partida se encuentra en las hipótesis de nivel superior, de las que se deben derivar otras hipótesis de menor generalidad hasta llegar finalmente a los enunciados observacionales que permitan la refutación de la teoría. Esta exposición es correcta en líneas generales, pero a nuestro entender presenta sólo un esquema parcial y excesivamente rústico de la propuesta de Popper.

\subsection{Conclusiones}

Si bien es cierto que existen grandes diferencias entre la explicación que Popper da de la tarea de investigación científica y el proceso de retroducción-abducción tal como surge de los trabajos de Hanson y Peirce, también es cierto que presentan muchos más puntos de contacto de lo que estábamos dispuestos a reconocer en un primer momento. Al mismo tiempo pueden inferirse de la propuesta de Popper algunos puntos de apertura hacia un enfoque retroductivo como complemento de su posición. Analizaremos en detalle cada una de estas afirmaciones.

\subsection{Puntos en común}

Tomando como base el marco teórico de referencia, la presencia

«Para que el explicans no sea ad hoc tiene que ser rico en contenido: debe tener una variedad de consecuencias contrastables que sean diferentes del explicandum. Son esas diferentes consecuencias contrastables en las que estoy pensando cuando hablo de contrastaciones independientes o de evidencia independiente» (1956: 172-173).

${ }^{29}$ (1934: 32-33). 
de anomalías o fenómenos sorprendentes es lo que pone en funcionamiento la tarea de investigación científica. En las dos posiciones se resalta la circunstancia de que se parte de hechos conocidos en busca de los enunciados que permitan explicarlos.

Se resalta el carácter conjetural del conocimiento científico.

Coinciden en algunas de las condiciones que deben reunir las hipótesis para ser aceptadas, por ejemplo la coherencia con los otros enunciados del marco teórico, la no falsedad evidente de las mismas, el carácter no tautológico y el contenido mayor del explicans respecto al explicandum.

\subsubsection{Puntos de fricción}

En Popper el proceso de formación de hipótesis no es susceptible de análisis filosófico, es materia de la psicología, mientras que la principal motivación para sostener un enfoque abductivista es poder explicitar los criterios de racionalidad que operan en dicha tarea, lo que constituye una labor que debe llevar adelante la filosofía de la ciencia.

El enfoque de Popper no atiende los problemas conceptuales, sólo presta atención a los aspectos lógicos de la tarea de contrastación de conjeturas, lo que se pone de manifiesto claramente con la asimilación que tiende a realizar entre explicación e interpretación en uno de los textos que hemos citado (ver supra). La retroducción-abducción en cambio centra sus incumbencias en el plano estrictamente conceptual. No por esto resta importancia a la contrastación empírica de las hipótesis, sino que intenta dar cuenta del procedimiento previo a la determinación de la verdad o falsedad de las conjeturas.

\subsubsection{Hacia la complementariedad de los enfoques}

Los enfoques retroductivos reconocen la importancia del procedimiento deductivo en la tarea de contrastación empírica de las hipótesis o teorías conjeturadas, a los efectos de determinar el grado de adecuación que las mismas tengan con la realidad. Pero sostienen que antes de la labor confirmatoria se debieron llevar a cabo tareas estrictamente conceptuales que también responden a criterios de racionalidad. Es cierto que en el planteo de Hanson a veces tienden a confundirse las tareas de interpretación de los datos con las relaciones lógicas que mantiene el explicans postulado con el resto de los enunciados que componen el marco de referencia, esto se pone de 
manifiesto cuando expresa como condición de aceptación de las hipótesis que las mismas puedan integrarse coherentemente en el modelo y que impliquen características independientes de las que presenta el explicandum, Pero, no obstante, es claro que en todo momento piensa la tarea de formulación y aceptación de hipótesis desde una perspectiva semántica.

En Popper en cambio encontramos, en una primera lectura, un rechazo explícito a que la filosofía de la ciencia se ocupe de cuestiones que ocurran antes de contar con un enunciado formulado con el carácter de hipótesis explicativa de los fenómenos sorprendentes. Por eso el énfasis en las cuestiones lógicas y la posibilidad de contrastación empírica.

No obstante podemos hallar en sus trabajos algunos elementos que permiten inferir la posibilidad de que, a pesar del rechazo expreso de Popper, la tarea conceptual que propone el enfoque retroductivo tenga un espacio en su propia propuesta sin caer en la esfera de la psicología.

Esos elementos son los siguientes: i) reconoce que las teorías cumplen la función de permitirnos interpretar nuestras experiencias (Popper, 1956: 156), aunque luego parece asimilar interpretación y explicación, podemos diferenciar con claridad ambas cuestiones. El problema de la interpretación, o reconocimiento de significación en ciertos hechos, ha sido objeto de reflexiones filosóficas en todas las épocas y durante este siglo ha llegado a convertirse en uno de los principales temas de estudio de la semiótica. Si bien la psicología también se ocupa de estas cuestiones no se puede negar la incumbencia de la filosofía en su elucidación; ii) así como marcamos en Hanson la mención de cuestiones lógicas entre las condiciones de aceptabilidad de una hipótesis, también en Popper podemos hallar elementos que hacen hincapié en aspectos semánticos de los enunciados hipotéticos como condición de contrastación. Popper sostiene como primer requisito que para ser satisfactoria una hipótesis explicativa no debe saberse que es falsa ni siquiera después del examen más crítico (Popper, 1956: 172). Para determinar la verdad o falsedad de la hipótesis, aun cuando para ello utilicemos un proceso deductivo, debemos previamente resolver problemas de tipo conceptual, como por ejemplo qué extensión tienen los términos con los que está formulada la hipótesis, la subsunción de los fenómenos sorprendentes en alguno de dichos términos, la determinación de aquellos elementos que consideraremos falsadores del enunciado, cuestiones que tienen que ver en última instancia con el significado de los términos con los que construimos nuestras hipótesis. Nuevamente hallamos elementos que no son reductibles a cuestiones psicológicas y que son objeto de genuinas reflexiones filosóficas. 
De esta manera no es aventurado reconocer que existe una esfera intermedia entre los aspectos lógicos y psicológicos de la tarea de conjeturar explicaciones científicas: es la esfera conceptual, de la que se ocupa principalmente la semiótica y en la que centran su interés los enfoques retroductivos. Es ésta un área que avanza sobre lo que comúnmente se denomina contexto de descubrimiento, por lo que sí permite precisar ciertos criterios de racionalidad en la resolución de las cuestiones que le son propias puede llegar a sugerir algunos de los procedimientos de descubrimiento que se están buscando.

Ambos enfoques, en caso de que este último logre sus objetivos, están llamados a complementarse para ofrecer una visión abarcadora y fértil de la búsqueda y construcción del conocimiento científico, sin abandonar en ningún momento el terreno de la filosofía de la ciencia.

\section{CONCLUSIONES Y PROYECCIONES}

Se ha mostrado la plausibilidad de un análisis filosófico de la formación de hipótesis utilizando para ello el enfoque abductivo-retroductivo. Se han señalado también las cuestiones que se deben resolver antes de poder contar con una reconstrucción de dicho procedimiento que pueda cumplir con los objetivos que persigue. Estas son i) la determinación de los criterios que deben guiar la selección de los caracteres que se considerarán relevantes en el fenómeno a explicar; ii) la explicitación de los mecanismos que permitan controlar intersubjetivamente la subsunción de los mismos en conceptos conocidos; iii) la formulación de los procedimientos de selección (o creación) de los conceptos a tener en cuenta antes de llevar a cabo la mencionada subsunción.

Creemos haber mostrado que hay que evitar el rechazo de la propuesta abductiva basándose en algunas caracterizaciones desafortunadas del procedimiento, como la que realiza Hanson de la retroducción, manteniendo abierta una discusión filosófica que puede dar resultados fructíferos.

En vista de los interrogantes que quedaron planteados consideramos que el enfoque semiótico al que hicimos mención en varias partes del trabajo se impone como paso próximo en esta tarea exploratoria que hemos encarado.

Umberto Eco ha desarrollado una propuesta semiótica a partir de las líneas que al respecto abrió Peirce, en cuyo seno la abducción no sólo es un instrumento para explicar cómo ciertos fenómenos naturales pueden operar como signos, sino que también es el 
elemento que permite explicar la significación de enunciados lingüísticos ${ }^{30}$.

Esto abre además una interesante posibilidad de aplicación en el campo del derecho, pues los resultados no se circunscribirían como señalamos en un primer momento a las inferencias que tienen por finalidad dar por probados ciertos hechos en el marco de un proceso judicial, sino que serían aplicables al otro gran grupo de operaciones que se llevan a cabo en dicho marco: la interpretación de los enunciados normativos.

Pero no debemos olvidar que antes de eso debemos hallar en la obra de Eco respuestas satisfactorias para las cuestiones que ni Peirce ni Hanson lograron resolver.

El próximo paso en esta línea de trabajo, por tanto, será el de adentrarnos en la extensa obra del semiólogo italiano a los efectos de encontrar (si es que existen) esas respuestas y determinar luego el grado de utilidad que la abducción puede prestar en el campo jurídico.

${ }^{30}$ Cfr. principalmente Eco 1975, 1984 y 1990. 


\section{BIBLIOGRAFÍA $\mathbf{A}^{31}$}

Alchourrón, Carlos E. y Bulygin, Eugenio (1989): «Los límites de la lógica y el razonamiento jurídico», en Alchourrón, Carlos E. y Bulygin, Eugenio, Análisis lógico y derecho, Madrid, Centro de Estudios Constitucionales, 1991, págs. 303-328.

(1991): Análisis lógico y derecho, Madrid, Centro de Estudios Constitucionales, 624 págs.

Atienza, Manuel (1991): Las razones del derecho. Teorías de la argumentación jurídica, Madrid, Centro de Estudios Constitucionales.

Bochenski, J. M. (1956): Historia de la Lógica Formal («Biblioteca de Filosofía»), Madrid, Gredos, 1966.

Bonfantini, Massimo A. y Proni, Giampaolo (1983): «To guess or not to guess?», en Eco, Umberto y Sebeok, Thomas (Eds.), El signo de los tres, Barcelona, Lumen, 1989, págs. 164 a 184.

Carettini, Gian Paolo (1983): «Peirce, Holmes, Popper», en Eco, Umberto y Sebeok, Thomas (Eds.), El signo de los tres, Barcelona, Lumen, 1989, págs. 185 a 209.

Conan Doyle, Sir Arthur (1887): Estudio en Escarlata, en Obras Completas de Sir Arthur Conan Doyle, Bs. As., Hyspamérica, 1983, Tomo II, págs. 11-110.

Churchland, Paul M. (1984): Materia y conciencia. Introducción contemporánea a la filosofía de la mente, Barcelona, Gedisa, 1992.

Eco Umberto (1968b): La estructura ausente, Introducción a la semiótica, Barcelona, Lumen, 1978. (1973): Signo, Barcelona, Labor, 1988.

(1975): Tratado de Semiótica General, Barcelona, Lumen, 1977.

(1979): Lector in Fábula, La Cooperación Interpretativa en el Texto Literario («Palabra en el Tiempo»), Barcelona, Lumen, 1981.

(1983): «Cuernos, cascos, zapatos: algunas hipótesis sobre tres tipos de abducción», en Eco, Umberto y Sebeok, Thomas (Eds.), El signo de los tres, Barcelona, Lumen, 1989, págs. 265 a 294.

(1984): Semiótica y Filosofía del Lenguaje («Palabra en el Tiempo»), Barcelona, Lumen, 1990.

(1985): De los espejos y otros ensayos, Barcelona, Lumen, 1988.

(1990): Los límites de la interpretación, Barcelona, Lumen, 1992.

${ }^{31}$ Se cita por la fecha de la primera edición, aunque se han suprimido los datos de la misma para reducir la extensión del trabajo. 
Eco, Umberto y Sebeok, Thomas A. (Eds.) (1983): El signo de los tres («Palabra en el Tiempo»), Barcelona, Lumen, 1989.

Garrido, Manuel (1974): Lógica Simbólica, Madrid, Tecnos, (6. ${ }^{a}$ reimpresión revisada, 1983).

Ginzburg, Carlo (1979): «Morelli, Freud y Sherlock Holmes: Indicios y método científico», en Eco, Umberto y Sebeok, Thomas (Eds.). El signo de los tres, Barcelona, Lumen, 1989, págs. 116 a 163.

(1986): Mitos, emblemas, indicios. Morfología e historia, Barcelona, Gedisa, 1989.

Gómez, Ricardo (s.f.): «Sobre la vigencia del concepto aristotélico de ciencia», Cuadernos del Instituto de Lógica y Filosofía de las ciencias, N. ${ }^{\circ}$ 2, La Plata, Facultad de Humanidades y Cs. de la Educación.

Haack Susan (1978): Filosofía de las lógicas, Madrid, Cátedra, 1982.

Hanson, Norwood Russell (1958): «Patrones de descubrimiento. Investigación de las bases conceptuales de la ciencia», en Patrones de descubrimiento. Observación y explicación, Madrid, Alianza, 1977 (2. ${ }^{\text {a }}$ ed., 1985), págs. 70-310.

(1971): «Observación y explicación: Guía de la filosofía de la ciencia», en Patrones de descubrimiento. Observación y explicación, Madrid, Alianza, 1977 (2.. ed., 1985), págs. 11-70.

(1977): Patrones de descubrimiento. Observación y explicación, Madrid, Alianza, 1985.

Harrowitz, Nancy (1983): «El modelo policíaco: Charles S. Peirce y Edgar Allan Poe», en Eco, Umberto y Sebeok, Thomas (Eds.), El signo de los tres, Barcelona, Lumen, 1989, págs. 241 a 264.

Klimovsky, Gregorio y De Assua, Miguel (1992): Corrientes epistemológicas contemporáneas, Bs. As., C.E.A.L.

Peirce, Charles Sanders (1865): «Lección sobre Kant», en El hombre, un signo. (El pragmatismo de Peirce), Barcelona, Crítica, 1988, págs. 39-57.

(1867a): «Sobre la clasificación natural de los argumentos», en Escritos lógicos, Madrid, Alianza, 1968, págs. 35-65.

(1867b): «De una nueva lista de categorías», en Escritos lógicos, Madrid, Alianza, 1968, págs. 66-85.

(1868): «Algunas consecuencias de cuatro incapacidades», en El hombre, un signo. (El pragmatismo de Peirce), Barcelona, Crítica, 1988, págs. 88-122.

(1871): «Las obras de George Berkeley», en El hombre, un signo. (El pragmatismo de Peirce), Barcelona, Crítica, 1988, págs. 58-87.

(1877): «La fijación de la creencia», en El hombre, un signo. (El pragmatismo de Peirce), Barcelona, Crítica, 1988, págs. 175-199.

(1878): «Cómo esclarecer nuestras ideas», en El hombre, un signo. (El pragmatismo de Peirce), Barcelona, Crítica, 1988, págs. 200-223.

(1888): «Sobre el álgebra de la lógica», en Escritos lógicos, Madrid, Alianza, 1968, págs. 86-149.

(1883): «La lógica de relativos», en Escritos lógicos, Madrid, Alianza, 1968, págs. 150-166.

(1885): «Sobre el álgebra de la lógica. Una contribución a la filosofía de la notación», en Escritos lógicos, Madrid, Alianza, 1968, págs. 167-202. 
(1892a): «La Ley de la mente», en El hombre, un signo. (El pragmatismo de Peirce), Barcelona, Crítica, 1988, págs. 251-280.

(1892b): «La crítica de argumentos», en Escritos lógicos, Madrid, Alianza, 1968, págs. 203-211.

(1892c): «Se introduce al lector en el tema de los relativos», en Escritos Lógicos, Madrid, Alianza, 1968, págs. 212-221.

(1893/1902): «Icono, índex y símbolo», en El hombre, un signo. (El pragmatismo de Peirce), Barcelona, Crítica, 1988, págs. 142-161.

(1896): «La lógica regenerada», en Escritos lógicos, Madrid, Alianza, 1968, págs. 222-243.

(1898): «Tópicos vitalmente importantes», en El hombre, un signo. (El pragmatismo de Peirce), Barcelona, Crítica, 1988, págs. 307-331.

(1901a): «Lógica», en Escritos lógicos, Madrid, Alianza, 1968, págs. 244-250.

(1901b): «Lógica (exacta)», en Escritos lógicos, Madrid, Alianza, 1968, págs. 251-258.

(1901c): «Relativos», en Escritos lógicos, Madrid, Alianza, 1968, págs. 259-264.

(1902): «¿Por qué estudiar lógica?», en El hombre, un signo. (El pragmatismo de Peirce), Barcelona, Crítica, 1988, págs. 332-391.

(1903a): «Casos degenerados», en El hombre, un signo. (El pragmatismo de Peirce), Barcelona, Crítica, 1988, págs. 161-173.

(1903b): «Tres tipos de razonamientos», en El hombre, un signo. (El pragmatismo de Peirce), Barcelona, Crítica, 1988, págs. 121-141.

(1903/1906): «Lógica, ética, estética», en El hombre, un signo. (El pragmatismo de Peirce), Barcelona, Crítica, 1988, págs. 281-306.

(1905): «Temas del pragmaticismo», en El hombre, un signo. (El pragmatismo de Peirce), Barcelona, Crítica, 1988, págs. 224-250.

(1968): Escritos lógicos, Madrid, Alianza, 264 págs. Introducción, selección y traducción de Pilar Castillo Criado.

(1986): La ciencia de la semiótica, Bs. As. Nueva Visión, 115 págs.

(1988): El hombre, un signo. (El pragmatismo de Peirce), Barcelona, Crítica, 428 págs. Tr. de José Vericat.

Popper, Karl R. (1934): La lógica de la investigación cientifica («Estructura y Función»), Bs. As., R.E.I., 1985.

(1956): Realismo y el objetivo de la ciencia. Post Scriptum a La lógica de la investigación científica, volumen I, Madrid, Tecnos, 1985.

(1957): «La ciencia: conjeturas y refutaciones», en Conjeturas y Refutaciones. El desarrollo del conocimiento científico, Bs. As. Barcelona-México, Paidós, 1983, págs. 57-93.

(1963): Conjeturas y refutaciones. El desarrollo del conocimiento científico, Bs. As.-Barcelona-México, Paidós, 1983 (3. ${ }^{a}$ reimp., 1991).

(1972): Conocimiento objetivo, un enfoque evolucionista, Madrid, Tecnos, 1974 (4. ${ }^{\mathrm{a}}$ ed., 1992).

Quine, Willard van Orman (1944): El sentido de la nueva lógica («Interciencia»), Bs. As., Nueva Visión, 1958.

(1950): Los métodos de la lógica, Edición Revisada, Barcelona, Ariel, 1962 (2ª ed., 1967). 
Rehder, Wulf (1979): «Sherlock Holmes, detective filósofo», en Eco, Umberto y Sebeok, Thomas (Eds.) El signo de los tres, Barcelona, Lumen, 1989, págs. 295 a 312.

Schuster, Félix Gustavo (1992): El método en las Ciencias Sociales («Los fundamentos de las ciencias en el hombre»), Bs. As., C.E.A.L.

(1993): «Racionalidad, conocimiento y método en ciencias sociales», en Nudler, Oscar y Klimonsky, Gregorio (comps.), La racionalidad en debate, Bsdd. As., C.E.A.L., págs. 207-215, Vol. II.

Sebeok, Thomas A. (1983): «One, two, three... uberty. (A modo de introducción)», en Eco, Umberto y Sebeok, Thomas (Eds.), El signo de los tres, Barcelona, Lumen, 1989, págs. 19 a 30.

Sebeok, Thomas A. y Umiker-Sebeok, Jean (1979): «Ya conoce usted mi método: Una confrontación entre Charles S. Peirce y Sherlock Holmes», en Eco, Umberto y Sebeok, Thomas (Eds.), El signo de los tres, Barcelona, Lumen, págs. 31 a 81.

Thibauld, Pierre (s.f.): La lógica de Charles Sanders Peirce. Del álgebra a los gráficos, Madrid, Paraninfo, 1982.

Truzzi, Marcello (1973): «Sherlock Holmes: Experto en psicología social aplicada», en Eco, Umberto y Sebeok, Thomas (Eds.), El signo de los tres, Barcelona, Lumen, 1989, págs. 82 a 115 . 